\title{
Formation of Amorphous Cu-Zr Alloy Powder by Mechanical Alloying
}

T.R. Chen

Department of Marine Engineering Materials Program National Taiwan Ocean University Keelung, Taiwan 202

P.Y. Lee

Department of Marine Engineering Materials Program National Taiwan Ocean University Keelung, Taiwan 202

Follow this and additional works at: https://jmstt.ntou.edu.tw/journal

Part of the Mechanical Engineering Commons

\section{Recommended Citation}

Chen, T.R. and Lee, P.Y. (1993) "Formation of Amorphous Cu-Zr Alloy Powder by Mechanical Alloying," Journal of Marine Science and Technology. Vol. 1: Iss. 1, Article 9.

DOI: $10.51400 / 2709-6998.2479$

Available at: https://jmstt.ntou.edu.tw/journal/vol1/iss1/9

This Research Article is brought to you for free and open access by Journal of Marine Science and Technology. It has been accepted for inclusion in Journal of Marine Science and Technology by an authorized editor of Journal of Marine Science and Technology. 


\title{
FORMATION OF AMORPHOUS CU-Zr ALLOY POWDER BY MECHANICAL ALLOYING
}

\author{
T.R. Chen and P.Y. Lee \\ Department of Marine Engineering Materials Program \\ National Taiwan Ocean University \\ Keelung, Taiwan 202
}

Key words: mechanical alloying, amorphous, intermetallic compound, crystallization.

\begin{abstract}
Amorphous $C u_{\mathrm{x}} Z r_{100 \cdot x}$ alloy powder has been synthesized in the range $20 \leq x \leq 80$ by mechanical alloying mixtures of $C u$ and $Z r$ powders. This range is larger than amorphous alloys produced by the vaporquenching technique. A mixture of amorphous and crystalline phases formed at the compositions of $C u_{10} Z r_{90}$ and $C u_{90} Z r_{10}$. Amorphous $C u_{\mathrm{x}} Z r_{100-x}$ alloy powder also has been synthesized in the range $20 \leq x \leq 60$ by mechanical alloying mixtures of intermetallic compound $C u_{9} Z r_{2}$ and $\mathrm{CuZr} 2$ powders. The temperature and activation energy for crystallization of the MA $\mathrm{Cu}-\mathrm{Zr}$ amorphous powders are higher than that for vaporquenched samples. The contamination by oxygen of MA samples might be explain the differences in thermal properties between MA $\mathrm{Cu}-\mathrm{Zr}$ amorphous powders and vapor-quenched $\mathrm{Cu}-\mathrm{Zr}$ samples.
\end{abstract}

\section{INTRODUCTION}

Mechanical alloying is a powder processing technique for producing composite metal powders with controlled microstructures [1]. It is performed in a high-energy ball mill, most frequently in a Spex mill (research scale) or a Szegvari attritor grinding mill (industrial scale). The process consists of repeated mechanical mixing, cold welding, fracturing, and rewelding of ultrafine alloy powder [1]. Mechanical alloying can produce homogeneous alloys from elements which cannot be alloyed by diffusion, sintering, or melting. Using this technique, it is possible to developed "synthetic" alloys with unique properties. The first fully amorphous alloy was prepared by Koch et al. [2] from $N i_{60} N b_{40}$ powder. Later, Schwarz et al. [3], Thompson and Politis [4] and Hellstern and Schultz [5] also prepared amorphous $\mathrm{Ni}-\mathrm{Ti}, \mathrm{Pd}-\mathrm{Ti}$ and $\mathrm{Zr}$ based alloys by this method. These results demonstrated that mechanical alloying is a very effective technique for procucing amorphous materials.

The present study describes the preparation, characterization, and thermal stability of amorphous $\mathrm{Cu}$ $\mathrm{Zr}$ alloy powder prepared by mechanical alloying of powder mixtures with different crystalline states: (1) mixtures of pure elemental powders, (2) mixtures of intermtallics powders.

\section{EXPERIMENTAL PROCEDURE}

Pure crystalline $\mathrm{Cu}$ and $\mathrm{Zr}$ powder were purchased from Strem Inc. and Alfa Products. The intermetallic compounds were prepared by arc melting together the component of pure elements in a partial pressure of pure argon, gettered by first melting a zirconium button. The homogeneous intermetallic compound buttons were crushed to powder in a mortar and pestal and the powder was screened to a size of less than $45 \mu \mathrm{m}$. Mechanical alloying was carried out in a Spex Mixer/Mill 8000. The ball to powder weight ratio was 2:1. After every one hour of the mechanical alloying process the vial was opened and a small amount of powder was removed for $X$-ray diffraction analysis. Powders before and after mechanical alloying were examined for traces of crystallinity by RIGAKU/MAX IIIA diffractometer using filtered $\mathrm{CuK \alpha}$ radiation (wavelength $=0.15418 \mathrm{~nm}$ ) with a graphite monochromator. The measurement was per- 
formed from $2 \theta=30^{\circ}$ to $2 \theta=80^{\circ}$ at a scan rate of $2^{\circ}$ $/ \mathrm{min}$ under $C u K \alpha$ radiation operated at $40 \mathrm{kV}$ and $15 \mathrm{~mA}$. The stability of the amorphous powders formed was measured by studying their thermal behavior in a differential scanning calorimeter (DSC). A Dupont 2000 thermal analyser was employed to perform such measurements. During measurement, samples were sealed in a copper pan and heated together with a reference pan (also copper) from room temperature to $1000^{\circ} \mathrm{K}$ at four different heating rates $(10,20,30,40$ $\mathrm{C} / \mathrm{min}$ ) in a purified argon atmosphere. The microstructural evolution during MA was followed with standard metallography method.

\section{RESULTS AND DISCUSSION}

\section{A. MA of Pure Elemental Powders}

\section{A-1. Amorphous Powder Formation}

Mechanical alloying (MA) of pure crystalline $\mathrm{Cu}$ and $\mathrm{Zr}$ powder was carried out at compositions $C u_{\mathrm{x}} Z r_{100-\mathrm{x}}$, where $10 \leq x \leq 90$. After a steady condition is reached during MA for $20 \leq x \leq 80$, the powder is amorphous. For $x=90$, the powders is a mixture of the amorphous phase and the terminal solid solution crystalline phase. Fig. 1 shows $X$-ray diffraction patterns of amorphous $\mathrm{Cu}-\mathrm{Zr}$ powders after mechanical alloying.

A typical study of the formation of amorphous $\mathrm{Cu}-\mathrm{Zr}$ alloy powder by MA a mixture of pure crystalline $C u$ and $Z r$ was carried out at the $C u_{60} Z r_{40}$ composition. The MA process was monitored by several techniques; $X$-ray diffraction and optical microscopy (OM) being the principal ones. The corresponding microstructural development during amorphization of the $C u_{60} Z r_{40}$ alloy was traced via OM. The OM micrographs in Fig. 2 illustrate the etched individual powder particle cross-section as a function of milling time. After $0.5 \mathrm{~h}$ of ball milling, a typically lamellar morphology with a high degree of alignment is formed. After 10h MA, the convoluted lamellar are no longer resolvable by OM. This indicates that the ball milling process has reached the completion stage of MA processing (Fig. 2f). A fully amorphous $C u_{60} Z r_{40}$ alloy powder can be obtained beyond $15 \mathrm{~h}$ MA. Fig. 3 shows a series of $X$-ray diffraction patterns taken at designate times during the ball milling of this alloy. After $0.5 \mathrm{~h}$ of ball milling, the intensity of $C u$ and $Z r$ diffraction peaks for the starting powders decreased rapidly. With further ball milling to $15 \mathrm{~h}$, only a broad diffraction peak existed after $15 \mathrm{~h}$ MA.

\section{A-2. Thermal Analysis}

Amorphous $\mathrm{Cu}-\mathrm{Zr}$ alloy powders were heated at different rates in the DSC in order to study the crystallization behavior. Fig. 4 shows crystallization temperature as a function of composition. The value for the crystallization temperature corresponds to a scan rate of $40 \mathrm{~K} / \mathrm{min}$. The maximum crystallization temperature is around 60 at $\% C u$. For $C u$ concentrations greater than 60 at $\% C u$, the crystallization temperature decreasesrapidly. The results of Kneller et al [6] showed a similar crystallization temperature-composition dependence, but with generally lower crystallization temperature values. The difference may be due to the fact that they carried out $X$-ray diffraction measurements on isothermally annealed samples to determine the crystallization temperature of their vapor-quenched materials i.e. a much slower effective heating rate).

The activation energies of the crystallization process were determined by Kissinger's peak shift method. This method involves application of the equation.

$$
\ln \left[\mathrm{C} /(\mathrm{Tp})^{2}\right]=-(\mathrm{Ec} / \mathrm{RTp})+\mathrm{A}
$$

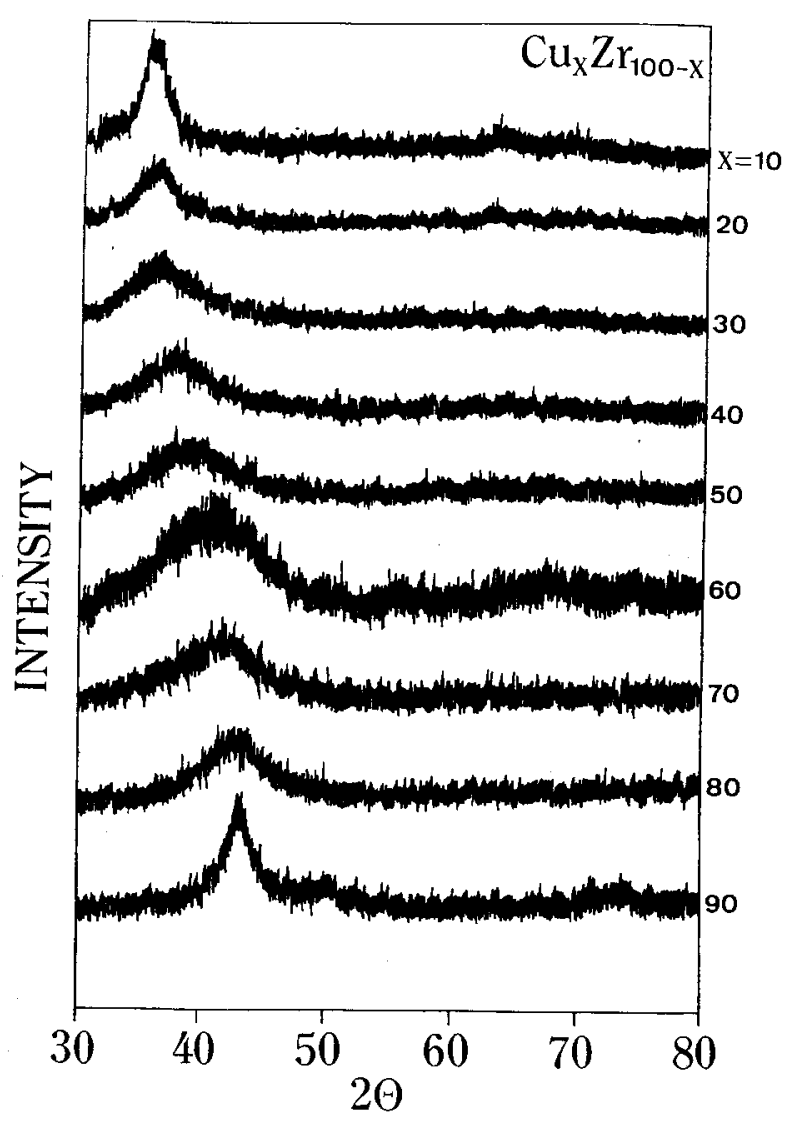

Fig. 1. $X$-ray Diffraction patterns of mechanically alloyed $C u_{x} Z r_{100-x}$ powders as a function of scattering angle. 

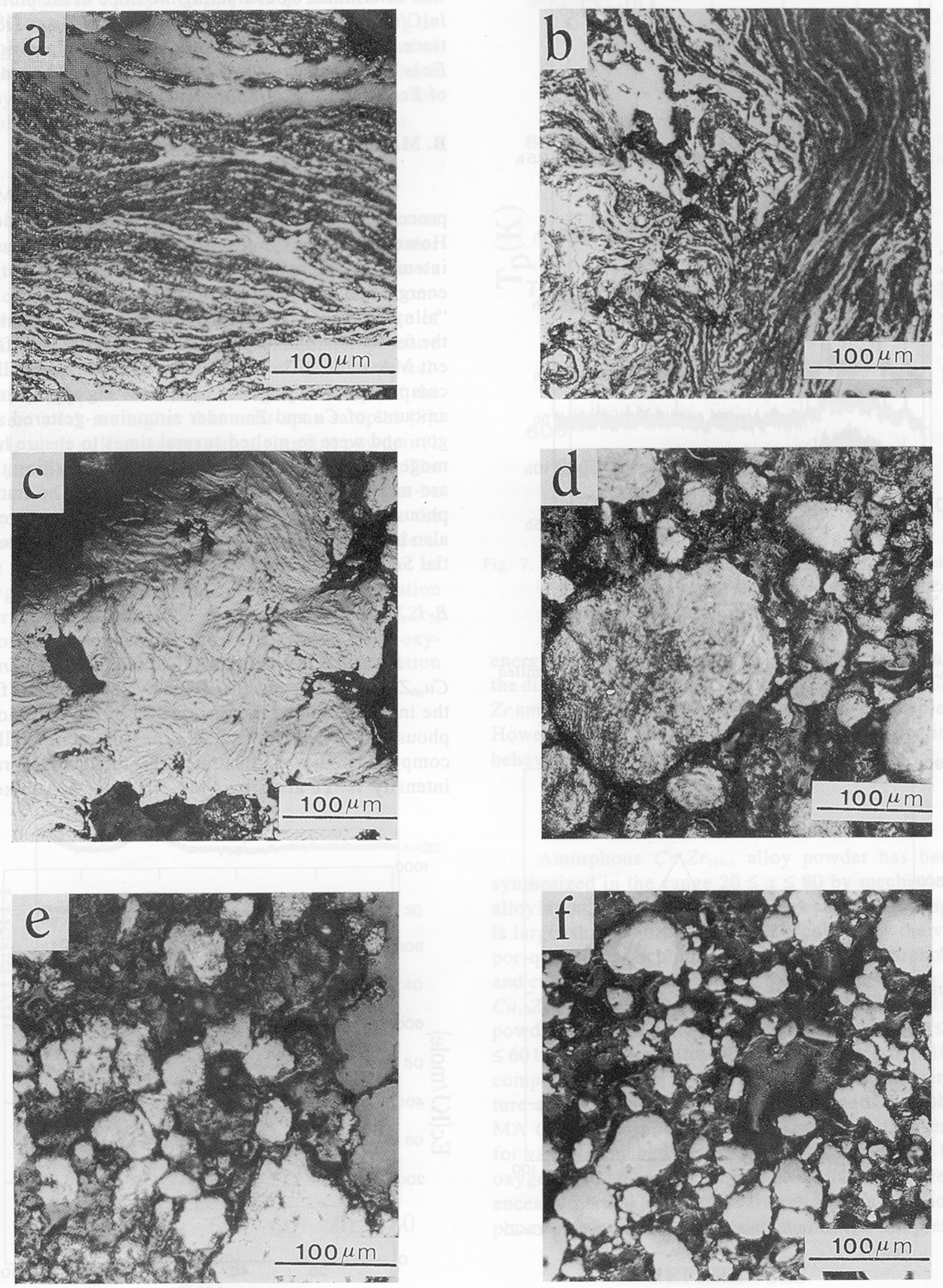

Fig. 2. Optical micrographs of $C u_{60} Z r_{40}$ powders at different milling stages. (a) $0.5 \mathrm{~h}$, (b) $\mathrm{lh}$, (c) $2 \mathrm{~h}$, (d) $5 \mathrm{~h}$, (e) $10 \mathrm{~h}$, (f) $15 \mathrm{~h}$. 


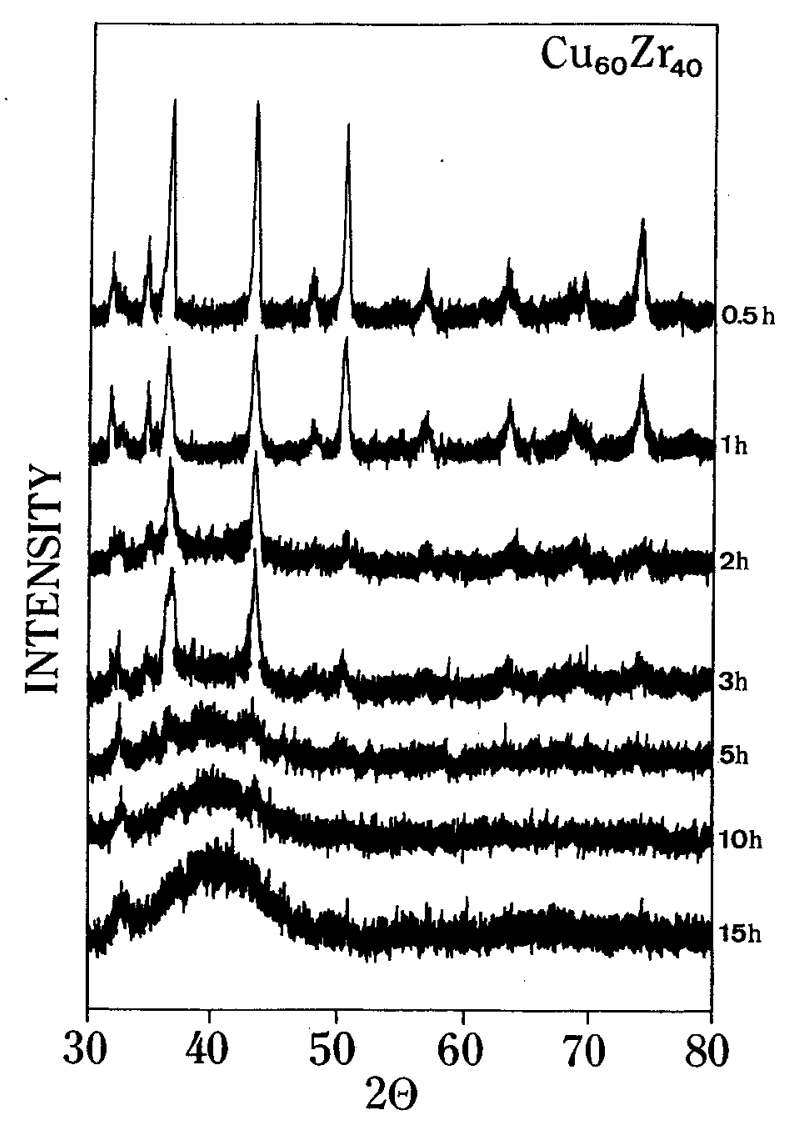

Fig. 3. X-ray diffraction patterns for $C u_{60} Z r_{40}$ powder milled for different time.

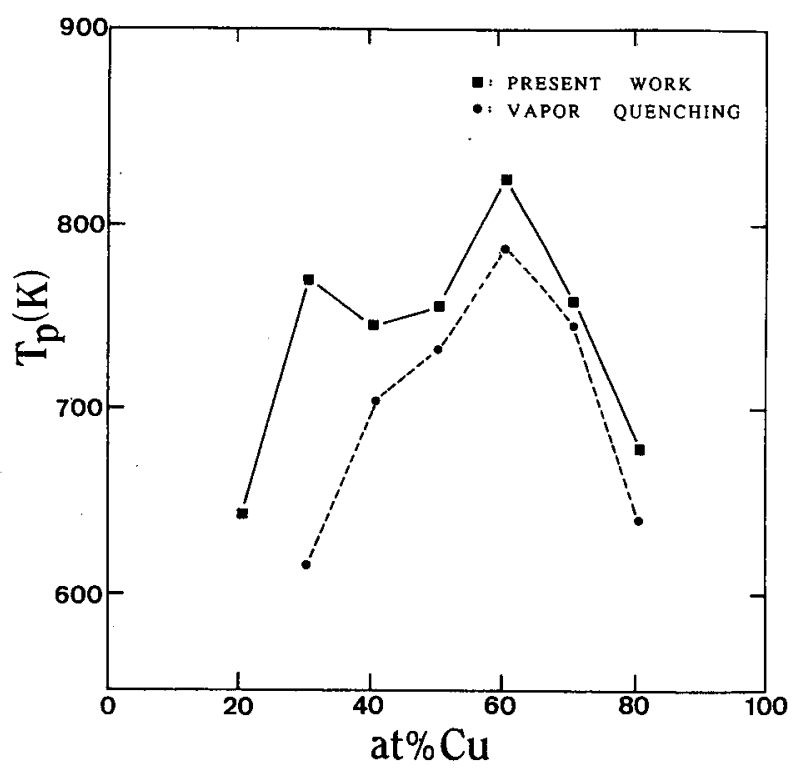

Fig. 4. The crystallization temperature for amorphous $\mathrm{Cu}-\mathrm{Zr}$ powers.

where $\mathrm{C}$ is the heating rate, $T p$ is the peak temperature, $E c$ is the activation energy and $\mathrm{R}, \mathrm{A}$ are constants. $E c$ was determined by evaluating the slope of the plot of $\ln \left[\mathrm{C} /(\mathrm{Tp})^{2}\right]$ against $1 / T p . T p$ can be derived from DSC trace. Fig. 5 shows $E c$ as a function of composition. $E c$ is highest at $C u-40$ at $\% Z r$ composition. The range of $E c$ is between $240 \mathrm{KJ} / \mathrm{mole}$ and $884 \mathrm{KJ} / \mathrm{mole}$.

\section{B. MA of Intermetallic Compounds}

The starting materials for amorphization by MA process are mixtures of pure crystalline powder. However, it has been shown that equilibrium intemetallic compounds can be amorphized by high energy ball milling [7] (not MA per se, since no "alloying" takes place). Therefore, we investigated the formation of amorphous $\mathrm{Cu}$-Zr alloys by a different MA route. The $C u_{9} Z_{2}$ and $C u Z r_{2}$ intermetallic compounds were prepared by arc melting appropriate amounts of $\mathrm{Cu}$ and $\mathrm{Zr}$ under zirconium-gettered argon, and were re-melted several times to ensure homogeneity. Powders were obtained by crushing the arc-melted buttons in a mortar and pestal. The amorphous $\mathrm{Cu}-\mathrm{Zr}$ powders formed by this method were also investigated by $X$-ray diffraction and Differential Scanning Calorimetry.

\section{B-1. X-ray Diffraction}

Five compostitions (Cu40Zr60, $C u_{50} Z r_{50}$, $C u_{60} Z r_{40}, C u_{70} Z r_{30}$ and $\left.C u_{80} Z r_{20}\right)$ have been chosen for the investigation of the formability of $\mathrm{Cu}-\mathrm{Zr}$ amorphous powder by MA of mixtures of intermetallic compounds. Fig. 6 illustrates the diffracted $X$-ray intensity vs. $2 \theta$ at various MA times for MA mixed

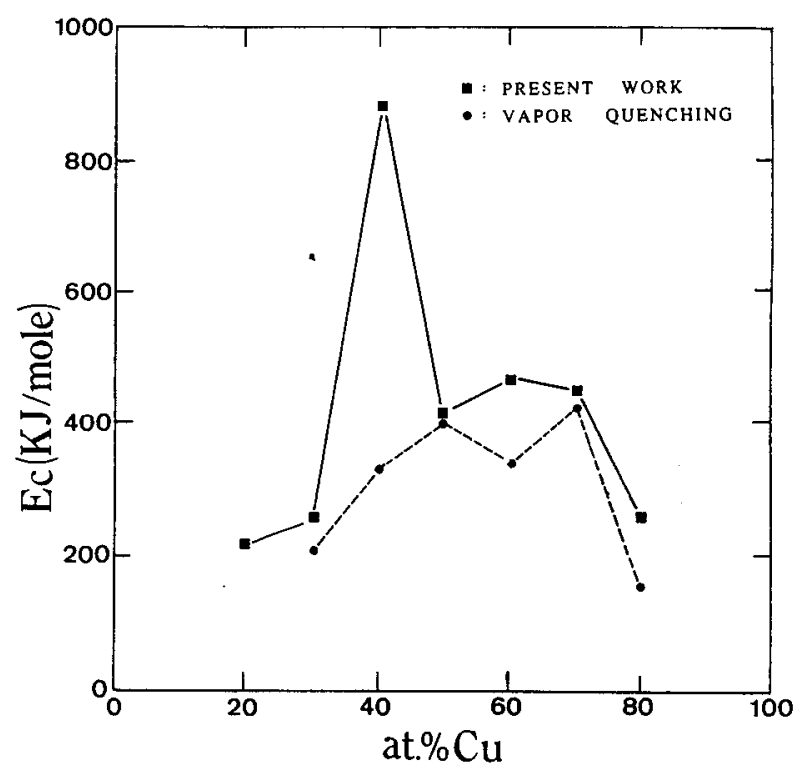

Fig. 5. Activation energy for the crystallization of amorphous $\mathrm{Cu}-\mathrm{Zr}$ powders. 
intermetallics $\mathrm{CuZr_{2 }}+\mathrm{Cu}_{9} \mathrm{Zr}_{2}$ which resulted in the amorphous $\mathrm{Cu}-\mathrm{Zr}$ alloy powder. By $15 \mathrm{~h}$ of milling no Bragg peaks can be detected above the background of the broad amorphous pattern. The structure of these alloys is considered to be essintially amorphous to the resolution of our $X$-ray diffraction measurements.

\section{B-2. Thermal Analysis}

The amorphous powders were heated at different rates in the differential scanning calorimeter in order to study their crystallization behavior. Fig. 7 shows the crystallization temperature as a function of composition. These values correspond to a scan rate of $40 \mathrm{~K} / \mathrm{min}$. A maximum in crystallization temperature was observed at a $Z r$ content near $40 \%$. The crystallization temperature of the amorphous alloys of the present work are higher than melt-spun samples [8]. MA is a ball milling process involving fine powders ( 1 to $5 \mu \mathrm{m}$ diam) and a large surface to volume ratio. The contamination by oxygen of MA samples might be larger than melt-spun samples and may influence the crystallization behavior of MA amorphous powders. Lee and Koch [9] have investigated the effect of oxygen content on the temperature and activation energy for crystallization of MA $N i_{40} Z r_{60}$ and $N i_{50} Z r_{50}$ amorphous powders. The results showed when oxygen content increases, the temperature and activation

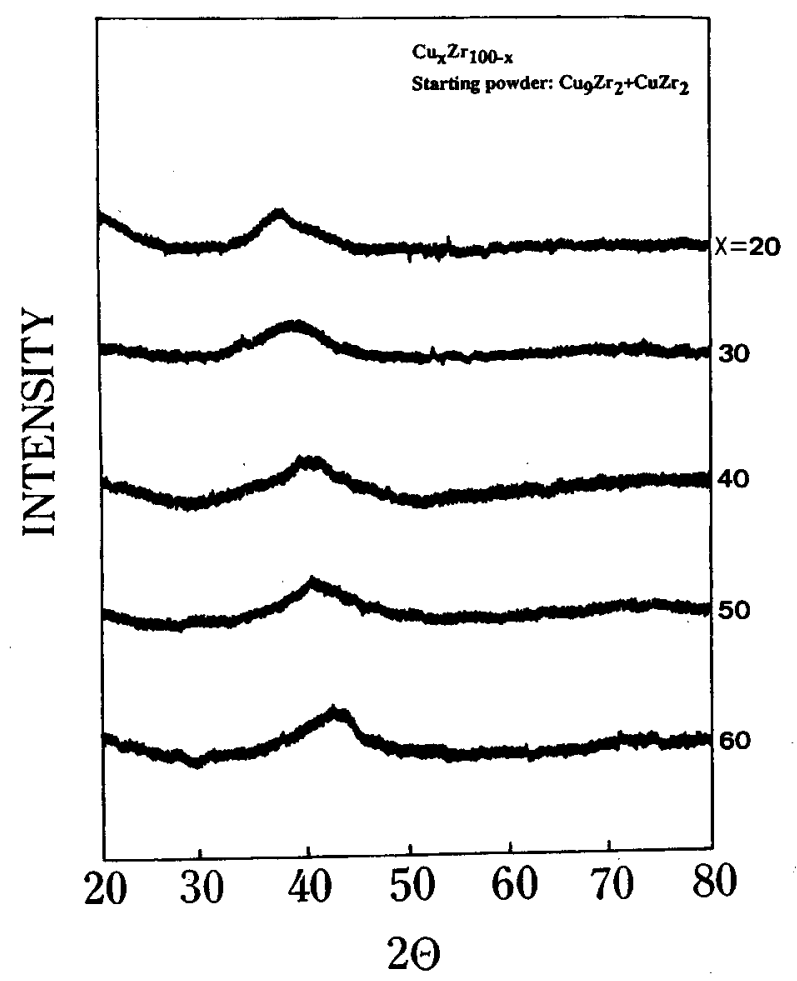

Fig. 6. $X$-ray Diffraction patterns of $C u_{x} Z r_{100-x}$ powders after me mechanical alloying with powder mixture of $\mathrm{Cu}_{9} \mathrm{Zr}_{2}$ and $\mathrm{CuZr}_{2}$.

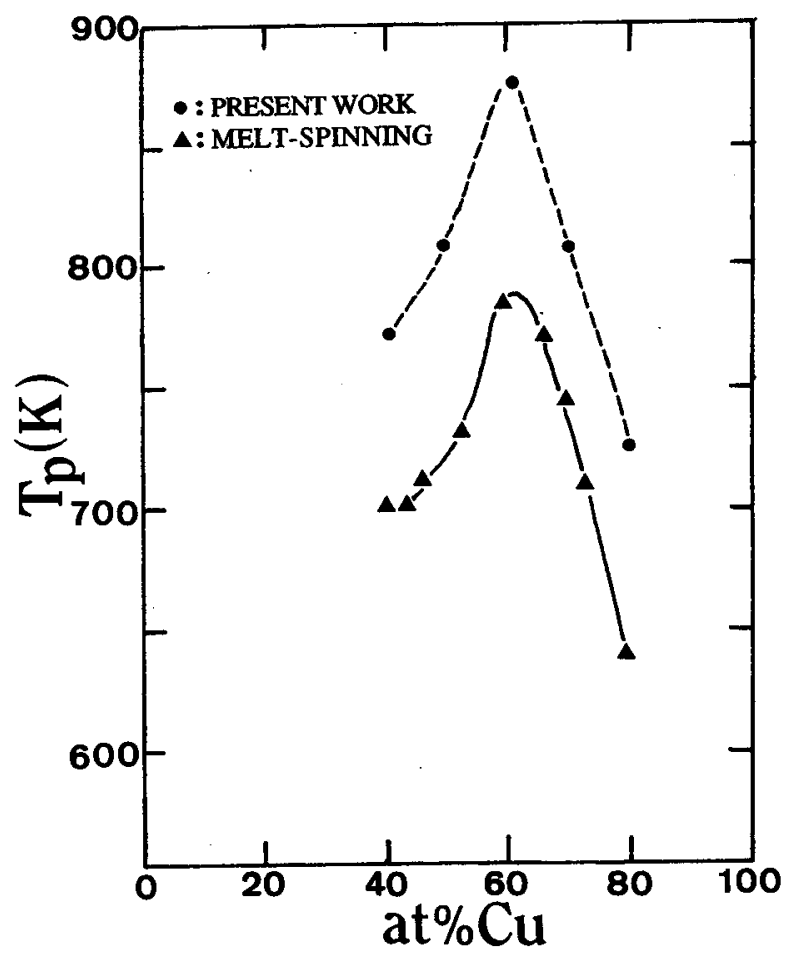

Fig. 7. The Crystallization temperature of $C u_{x} Z r_{100-x}$ powders after mechanical alloying with powder mixture of $C u_{4} Z r_{2}$ and $\mathrm{CuZr}_{2}$.

energy for crystallization increases. This may explain the differences in thermal properties between MA $\mathrm{Cu}$ $\mathrm{Zr}$ amorphous powders and melt-spun $\mathrm{Cu}$ - $\mathrm{Zr}$ samples. However, a more detailed study of crystallization behavior of MA amorphous powder is needed.

\section{CONCLUSIONS}

Amorphous $C u_{\mathrm{x}} Z r_{100-\mathrm{x}}$ alloy powder has been synthesized in the range $20 \leq x \leq 80$ by mechanical alloying mixtures of $\mathrm{Cu}$ and $\mathrm{Zr}$ powders. This range is larger than amorphous alloys produced by the vapor-quenching technique. A mixture of amorphous and crystalline phases formed at the compositions of $C u_{10} Z r_{90}$ and $C u_{90} Z r_{10}$. Amorphous $C u_{x} Z r_{100-x}$ alloy powder also has been synthesized in the range $20 \leq x$ $\leq 60$ by mechanical alloying mixtures of intermetallic compound $\mathrm{Cu}_{9} \mathrm{Zr}_{2}$ and $\mathrm{CuZr}_{2}$ powders. The temperature and activation energy for crystallization of the MA $\mathrm{Cu}-\mathrm{Zr}$ amorphous powders are higher than that for vapor-quenched samples. The contamination by oxygen of MA samples might be explain the differences in thermal properties between MA Cu-Zramorphous powders and vapor-quenched $\mathrm{Cu}-\mathrm{Zr}$ samples.

\section{REFERENCES}

1. Benjamin, J.S., "Mechanical Alloying", Sci. Amer., Vol. 234, pp. 40-67 (1976). 
2. Koch, C.C., O.B. Cavin, O.G. Mckamey, and J.O. Scarbrough, "Preparation of Amorphous $N i_{60} N b_{40}$ by Mechanical Alloying", Appl. phys. Lett., Vol. 48, pp. 124-126 (1983).

3. Schwarz, R.B., R . R. Petrich and C . K . Saw, "The Synthesis of Amorphous Ni-Ti Alloy Powders by Mechanical Alloying", J. Non-Crystall . Solids, Vol. 76, pp. 281-295 (1986).

4. Thompson, J.R. and C. Politis, "Formation of Amor -phous Ti-Pd Alloys by Mechanical Alloying Methods", Europhysics Letters, Vol. 3, pp. 199-205 (1987).

5. Hllstern, E and L . Schultz, "Glass Forming Ability in Mechanically Alloyed $\mathrm{Fe}-\mathrm{Zr}$ ", Appl . Phys . Lett., Vol. 48, pp. 124-126 (1986) .

6. Kneller, E., Y. Khan, and U . Gorres, "The Alloy System Copper-Zirconium, Part II: Crystallization of the Glasses from $C u_{70} Z r_{30}$ to $C_{26} Z_{74} ", Z$. Metallkd., Vol. 77, pp. 152-161 (1986).

7. Schwarz, R.B. and C. C. Koch, "Formation of Amorphous Alloys by the Mechanical Alloying of Crystalline Powders of Pure Metals and Powders of Intermetallics", Appl. Phys. Lett., Vol. 49, pp. 146-148 (1986)

8. Buschow, K.H.J., "Short-range Order and Thermal Stability in a Amorphous Alloys", J. Phys . F. Met. Phys., Vol. 14, pp. 593-602 (1984) .

9. Lee, P.Y. and C. C. Koch, "Formation of Amor phous Ni-Zr Alloy Powder by Mechanical Alloying of Intermetallic Powder Mixtures and Mixtures of Nickel or Zirconium with Intermetallics", J. Mater. Sci., Vol. 23, pp. 2837-2845 (1988) . 